\title{
Ovarian Transitional Cell Tumor
}

National Cancer Institute

\section{Source}

National Cancer Institute. Ovarian Transitional Cell Tumor. NCI Thesaurus. Code C7280.

A benign, borderline, or malignant epithelial tumor that arises from the ovary and is characterized by the presence of neoplastic cells that resemble urothelial cells and their neoplastic counterparts. This category includes benign Brenner tumor, borderline Brenner tumor, malignant Brenner tumor, and transitional cell carcinoma. 